\title{
Abrasion Behavior of High Manganese Steel under Low Impact Energy and Corrosive Conditions
}

\author{
Du Xiaodong, ${ }^{1}$ Sun Guodong, ${ }^{2}$ Wang Yifei, ${ }^{1}$ Wang Jianfeng,, ${ }^{1}$ and Yang Haoyu ${ }^{1}$ \\ ${ }^{1}$ School of Materials Science and Engineering, Hefei University of Technology, Hefei 230009, China \\ ${ }^{2}$ School of Materials Science and Engineering, Jiujiang University, Jiujiang 332005, China \\ Correspondence should be addressed to Du Xiaodong, hfutdxd@126.com
}

Received 2 February 2009; Revised 6 July 2009; Accepted 22 August 2009

Recommended by Dae Eun Kim

The abrasion behavior of high manganese steel is investigated under three levels of impact energy in acid-ironstone slurry. The wear test was carried out by an MLDF-10 tester with impact energy of $0.7 \mathrm{~J}, 1.2 \mathrm{~J}$, and $1.7 \mathrm{~J}$. The impact abrasion property of high manganese steel in corrosive condition was compared according to the wear mass loss curves. The wear mechanism was analysed by the SEM analysis of the worn surface and the optical metallographic analysis of the vertical section to the wear surface. The results show that the impact energy has a great effect on the impact corrosion and abrasion properties of it. Its abrasion mechanism in corrosive condition is mainly microplough and breakage of plastic deformed ridges and wedges under the impact energy of $0.7 \mathrm{~J}$. It is mainly the spelling of plastic deformed ridges and wedges under $1.2 \mathrm{~J}$ and the spalling of the work-hardening layer under $1.7 \mathrm{~J}$ after a long time testing.

Copyright (C) 2009 Du Xiaodong et al. This is an open access article distributed under the Creative Commons Attribution License, which permits unrestricted use, distribution, and reproduction in any medium, provided the original work is properly cited.

\section{Introduction}

After invented by Robert Hadfield in 1882, the high manganese steel (HMS) is still used for railroad components such as crossings and rock-handling equipment because of an enormous capacity for work-hardening upon impact [1].

Lining board is widely used in wet-grinding machine, metallurgical mines, electric power industry, and so on. HMS consists of Austenite after water-quenched according to the normal heat-treatment process and has low hardness [2]. But it is a typical wear resistance material when it is used under high load to produce work-hardening. So it is used widely as lining board. As the liner of the wet-grinding machine, the HMS bears not only impact and abrasion but also the corrosion of slurry. At present, part researchers devote themselves to investigate the effect of HMS concentrate on wear mechanism under high load [3, 4]. Many researchers try to improve the properties of the HMS with second phase particles [5-7]. There are a few of research concerning the impact and abrasion properties of the HMS in corrosive condition. In high-load condition, the wear resistance can be increased by work hardening, and the wear mass loss mainly comes from the spring of harden lay. But for some lining boards used in wet-grinding machine, the load is not too high to get heavy work hardening. Now, the lining boards run in lower energy impact, abrasion and corrosion condition. Therefore, it is very meaningful to investigate the impact corrosion and abrasion mechanism of the HMS in low impact energy.

\section{Experimental}

2.1. Experimental Material. The composition of HMS used in this experiment is shown in Table 1. After water quenched from $1050^{\circ} \mathrm{C}$, single-phase austenite was obtained, whose hardness is $226 \mathrm{HB}$, and impact toughness is $147 \mathrm{~J} \mathrm{~cm}^{-2}$, as shown in Table 1. Impact toughness $\left(a_{k}\right.$, defined as the sample absorbing impact energy divided-by cross section area of the sample) was measured according to Mesnager criterion; the sample size was $10 \mathrm{~mm} \times 10 \mathrm{~mm} \times 55 \mathrm{~mm}$.

2.2. Impact Corrosion and Abrasion Tests. The impact corrosion and abrasion tester used in this investigate was a MLDF-10 tester. as shown in Figure 1. The size of the impact corrosion and abrasion sample was $10 \mathrm{~mm} \times 10 \mathrm{~mm} \times 30 \mathrm{~mm}$. The samples were cleaned in the supersonic wave cleaning machine with acetone before the test, then were fixed on the 
TABLE 1: Chemical composition and mechanical properties of HMS.

\begin{tabular}{ccccccccccccccc}
\hline \multicolumn{1}{c}{ Materials } & \multicolumn{11}{c}{ Chemical composition } & \multicolumn{1}{c}{ Mechanical properties } \\
\hline \multicolumn{1}{c}{} & & $\mathrm{C}$ & $\mathrm{Mn}$ & $\mathrm{Cr}$ & $\mathrm{Ni}$ & $\mathrm{Mo}$ & $\mathrm{Si}$ & $\mathrm{RE}$ & $\mathrm{S}$ & & $\mathrm{P}$ & $\mathrm{HB}$ & $a_{k} / \mathrm{J} \mathrm{cm}^{-2}$ \\
HMS & 1.1 & 13 & - & - & - & 0.55 & 0.03 & $<0.03$ & $<0.07$ & & 226 & $>147$ & \\
\hline
\end{tabular}

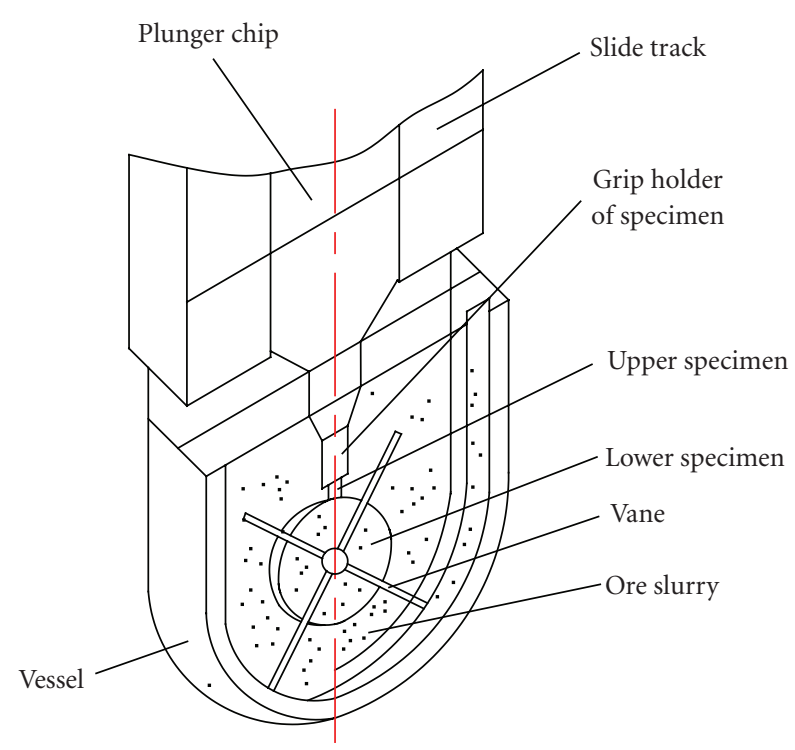

Figure 1: Schematic diagram of the impact corrosion-abrasion tester.

tester after drying and weighing. To simulate the running condition, the mixture of ironstone and water, whose volume radio was $3: 5$, was used as the medium. The grain size of the ironstone was 3-5 mm, and its microhardness was 766$1097 \mathrm{HV}$. The $\mathrm{pH}$ value of the slurry was 2.0-2.5. The upper sample moved up and down reciprocally with the impact hammer, and the lower sample, which was made of GCr15 steel, rotated continually. The ironstone abrasive materials entered into the space between the friction surfaces under the function of the agitating service. The impact energy, which was measured according to the height of upper sample's fall, was $0.7 \mathrm{~J}, 1.2 \mathrm{~J}$, and $1.7 \mathrm{~J}$, respectively. The sample stood impact corrosion and abrasion continuously and was cleaned every 2 hours in supersonic wave cleaning machine with acetone and then dried and weighed. The mass loss of the samples was measured and then the average value of three kinds sample was calculated. The worn surface was observed by a Sirion-200 FEG SEM, the subsurface microstructure of the samples was analyzed by Olympus optical metallographic microscope, and then the impact and corrosion abrasion mechanism of the HMS was discussed.

\section{Result and Discussion}

3.1. Impact Corrosion and Abrasion Properties of the HMS at Different Impact Energy. The relationship between the wear mass loss and wear time of the HMS in acid-ironstone slurry under three levels of impact energy is shown in Figure 2. In

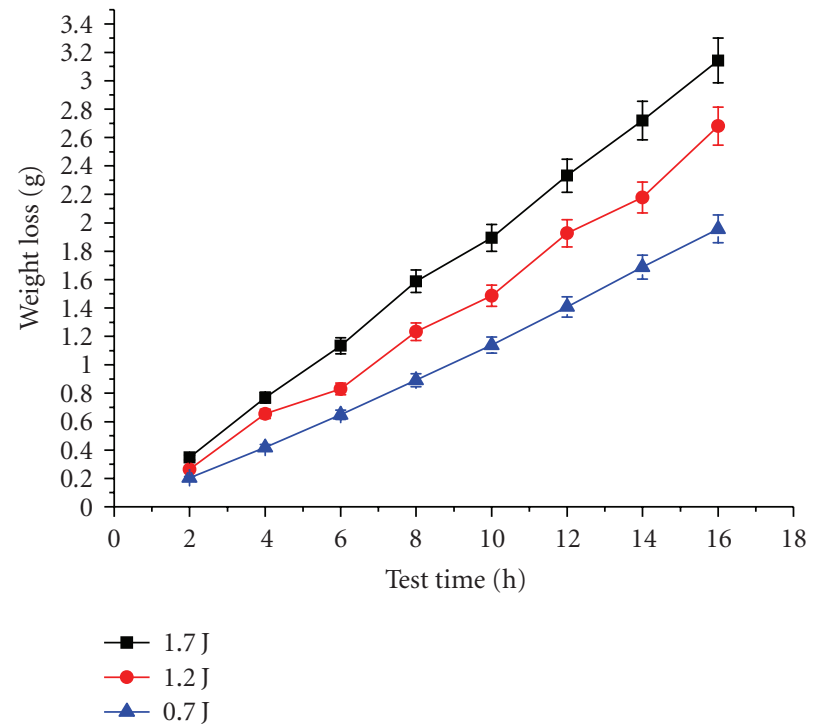

Figure 2: Relation between the wear loss and wear time of the HMS in acid-ironstone slurry at different impact energies.

the same test time, the wear mass loss of the steel increases along with the increment of the impact energy, which shows that the impact energy is an important factor in the impact corrosion and abrasion condition. The wear mass loss curve of the HMS seems to be linear as a function of test time at the impact energy of $0.7 \mathrm{~J}, 1.2 \mathrm{~J}$, and $1.7 \mathrm{~J}$ during 2-16 hours, which indicates that the wear mechanism may be constant in such condition. The slope of the curve under $0.7 \mathrm{~J}$ is less than that of the others. And for $1.7 \mathrm{~J}$, the slope is the largest in those three curves. Their wear mechanism will be analysed in Section 3.2.

\subsection{Abrasion Mechanism of HMS under Different Impact Energy}

3.2.1. Abrasion Mechanism under 0.7J. The worn surface morphology of the HMS (Figures 3(a), 3(b)) after worn in acid-ironstone slurry for 8 hours and 16 hours, respectively, shows that there are many furrows and a few of small pits on the wear surface. When the test time is extended to 16 hours, some small-massive or banding plastic deformed ridge occurs, and the ploughing is serious than that at 8 hours.

When solid particles impinged on a metal at a high impact angle, the removal of material is mainly due to the repeated plastic deformation. Because of the low hardness of HMS before obvious work-hardening occurs, the abrasive particles could be pressed into the surface of the steel by 


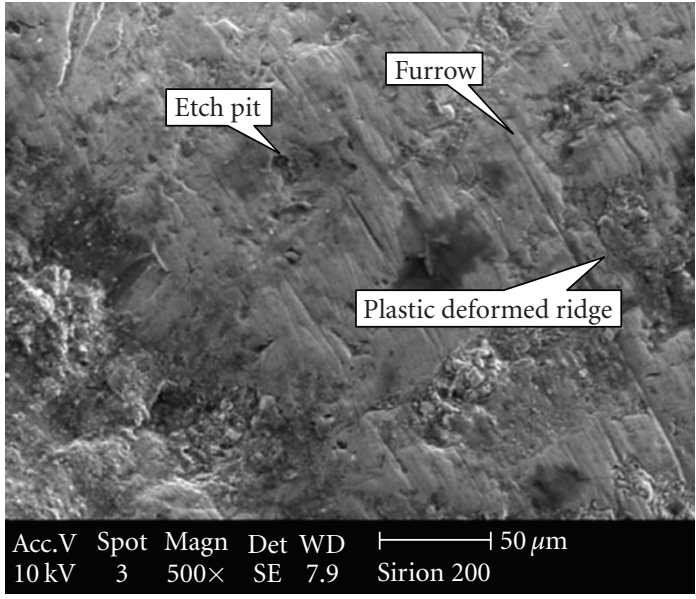

(a) 8 hours

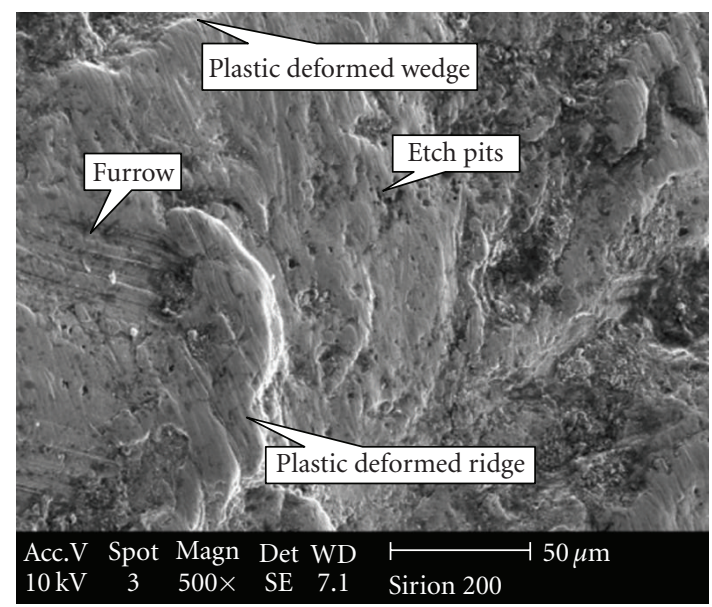

(b) 16 hours

FIgURE 3: Worn surface morphology after impact-corrosion wear for 8 hours and 16 hours at the impact energy of $0.7 \mathrm{~J}$.

the normal stress. At the same time, the abrasive particles glided along the wear surface, and the furrows formed. Since the toughness of the HMS was high and the impact energy was lower, the chip was not easy to be formed and only the microplough occurred. The material which was pushed to the sides of the furrow formed plastic deformed ridges, and the material which was pushed to the frontage of the furrow formed plastic deformed wedges. The ridges and wedges became more and larger after repeated plastic deformation. During the subsequent wear process, these salient areas were repeatedly impacted or deformed and broke down at last to form grindings.

In addition, there were less etch pits on worn surface after worn for 8 hours, and the corrosion produce and other trace of corrosion could not be found, which implied that the corrosion might have not distinct action to the impact abrasion of HMS in such condition. After worn for 16 hours, the number of etch pits increased obviously. It might be the combined action of stress and corrosion.

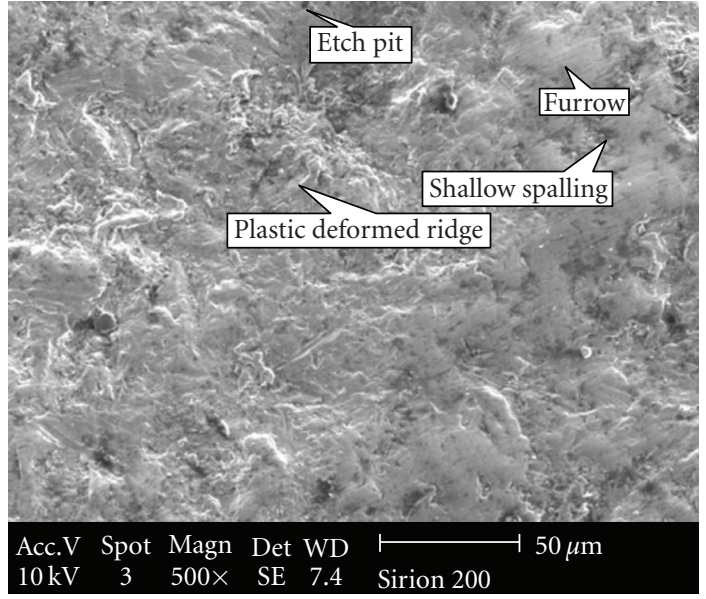

(a) 8 hours

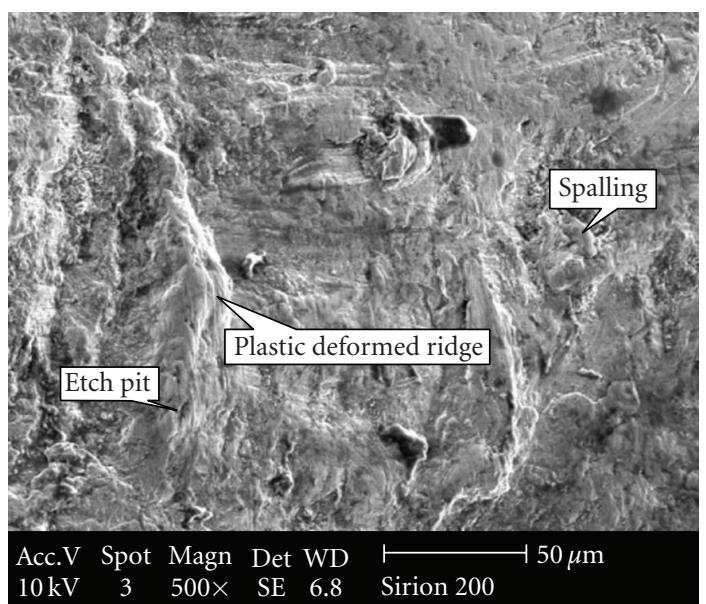

(b) 16 hours

FigURE 4: Worn surface morphology after impact-corrosion wear for 8 hours and 16 hours at the impact energy of $1.2 \mathrm{~J}$.

3.2.2. Abrasion Mechanism under 1.2 J. The worn surface morphology of the HMS after impact worn for 8 hours and 16 hours at the impact energy of $1.2 \mathrm{~J}$ can be seen from Figure 4. As shown in Figure 4(a), the number of the furrows decreased, but the number of plastic deformed ridges and wedges increased obviously. The fresh surface was exposed because of the spalling of plastic deformed ridges and wedges, which made the furrows shorter. With the extension of test time, the extruding and spalling of superficial layer were aggravated and the furrow became obscure as shown in Figure 4(b).

The above phenomenon has a close relationship with the properties of HMS and the impact energy. The composition of HMS was austenite entirely before worn. Under the effect of impact force, the deformation could have it work hardened. Obviously, when the impact energy increases, the deformation and extruding would increase and the plastic deformed ridge and wedge became more and larger. At the same time, the resistance of the abrasive particles gliding 


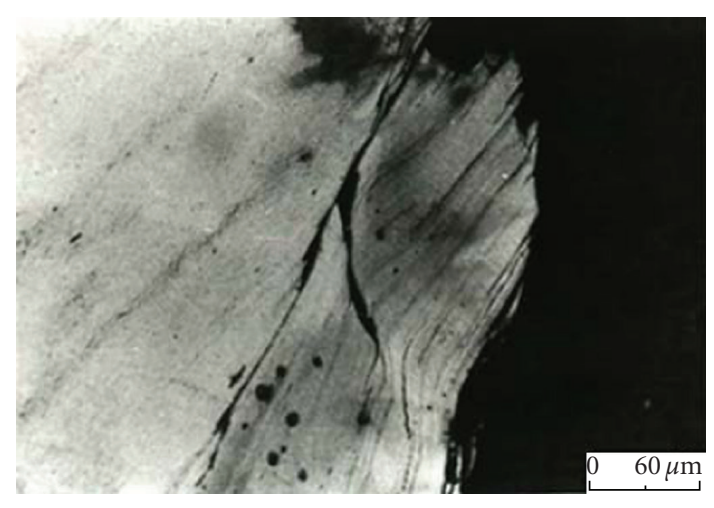

FIgURE 5: Optical metallograph of vertical section after impactcorrosion wear for 8 hours and 16 hours at the impact energy of $1.2 \mathrm{~J}$.

along the wear surface was increased. As a result, the number and length of the furrows decreased.

Plastic deformation and work-hardening occurred when the plastic deformed ridges and wedges formed. There would be many dislocations in the plastic deformed ridges and wedges, which could decrease the toughness and increased the break possibility of it. The microcracking was easy to form at the interface of the hardened area and the unhardened area, which caused the fracture along the root of the plastic deformed ridges and wedges (as shown in Figure 5).

The small etch pits in the worn surface were the result of the corrosion. The HMS formed the plastic deformed ridges and wedges during the impact wear process, and the salient areas had a higher internal energies than that of the cupped areas. In corrosive media, the deformation cell formed, in which the salient areas was the anode, the cupped areas acted as the cathode [8]. Because the HMS has good corrosion resistance itself, and the deformation amount of the tested steel is not very large, only some small etch pits formed on the surface of the steel.

3.2.3. Abrasion Mechanism under 1.7 J. The morphologies of the worn surface after impact wear for 8 hours and 16 hours at the impact energy of $1.7 \mathrm{~J}$ are shown in Figure 6. It can be seen that the fresh surface of material occupied the majority area of wear surface, which indicated that the spelling was the dominate wear mechanism in this condition. There were plastic deformed ridges and wedges and small corrosion pits on the worn surface too. It can be seen from Figure 6(b) that a big block material would spall from the wear surface after worn for 16 hours.

According to the delamination theory of N. P. Suh and Y. Y. Yang [9], the process of wear mass loss is the process in which the microcracking and the cavity form at the subsurface, extend parallel to the surface and return to the surface at the weak areas, lead local areas of the surface to spall at last. Under the impact load, the deformation layer was formed near the wear surface, in which the tangle and crossing of the dislocations led to the word-hardening of it (Figure 7). At last the microcracking occurred at the boundary of

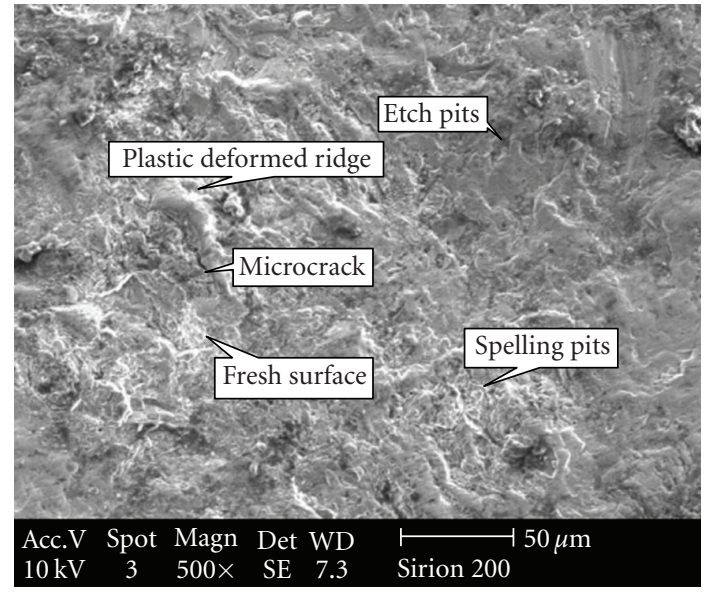

(a)

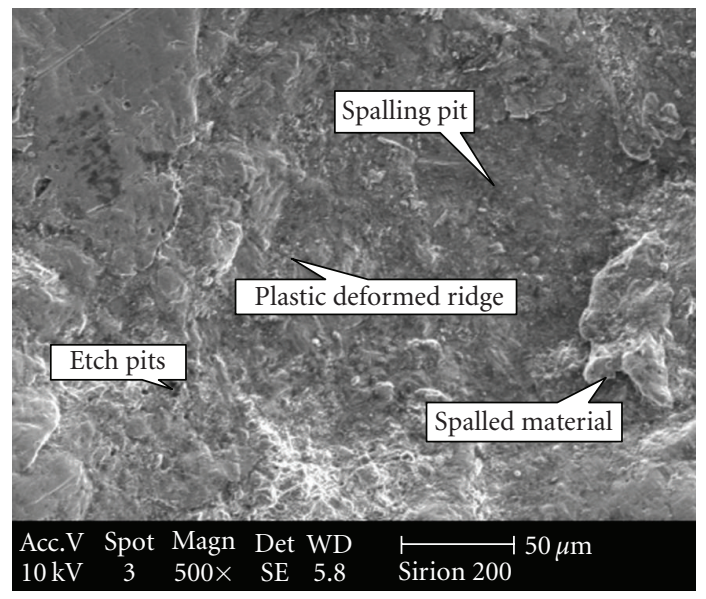

(b)

FIGURE 6: Worn surface morphology after impact-corrosion wear for 8 hours and 16 hours at the impact energy of $1.7 \mathrm{~J}$.

the hardened layer and the unhardened layer (Figure 8). After impact corrosion and abraded for a long time, the microcracking extended to the wear surface and the corrosive medium infiltrated into the microcracking (the phenophone of crack branching and secondary microcracking can be seen from Figure 8), which would aggravate the growth of the microcracking and the corrosion of the materials and lead to the spalling of the hardened layer finally (Figure 8). Because of the interaction of the impact corrosion and abrasion, the wear loss was the maximal in this condition.

\section{Conclusions}

(1) During the impact corrosion and abrasion, the wear mass loss of the high manganese steel increases along with the increasing of the impact energy. The impact energy has a great effect on the impact corrosion and abrasion properties of the high manganese steel.

(2) In acid-ironstone slurry, the impact corrosion and abrasion mechanism of the high manganese steel is mainly 


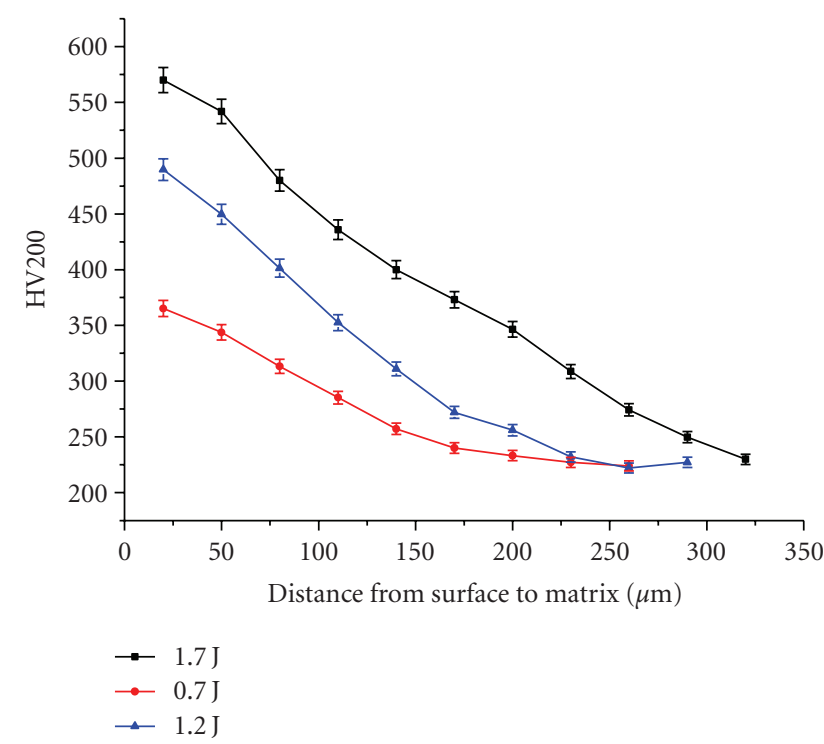

Figure 7: Curves of microhardness of the HMS after impactcorrosion wear for 16 hours.

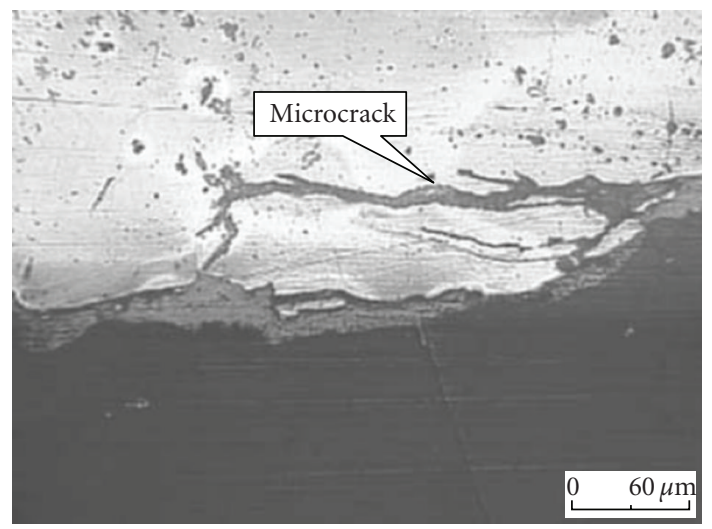

Figure 8: Optical metallograph of vertical section after impactcorrosion wear for 8 hours and 16 hours at the impact energy of $1.7 \mathrm{~J}$.

microplough and breakage of plastic deformed ridges and wedges under the impact energy of $0.7 \mathrm{~J}$. When the impact energy is $1.2 \mathrm{~J}$, it is microplough and secondary microcutting in a short time. With the extension of test time, the wear mechanism changed to spelling of the plastic deformed ridges and wedges. When the impact energy is $1.7 \mathrm{~J}$, the wear mechanism is mainly the spalling of the work-hardening layer after a long time testing.

\section{Acknowledgments}

The author acknowledges financial support for this work from the Natural Science Research Fund of Education Bureau of Anhui Province (KJ2009A094), Doctor's Special Research Fund of Hefei University of Technology and The Innovation Fund for Small Technology-based Firms (09C26213404170).

\section{References}

[1] R. W. Smith, A. de Monte, and W. B. F. Mackay, "Development of high-manganese steels for heavy duty cast-to-shape applications," Journal of Materials Processing Technology, vol. 153-154, no. 1-3, pp. 589-595, 2004.

[2] Z.-M. He, Q.-C. Jiang, X.-B. Fu, and J.-P. Xie, "Improved workhardening ability and wear resistance of austenitic manganese steel under non-severe impact-loading conditions," Wear, vol. 120, no. 3, pp. 305-319, 1987.

[3] F.-Q. Zu, X.-Y. Li, L.-J. Liu, and W. Wu, "Research on microstructure and work hardening mechanism of high manganese steel by simulating actual working condition," Transactions of Materials and Heat Treatment, vol. 27, no. 2, pp. 71-74, 2006.

[4] L. Fang, Y.-H. Xu, Q.-H. Cen, and J.-H. Zhu, "Impact wear behaviors of Hadfield manganese steel," Journal of Central South University of Technology, vol. 12, no. 2, pp. 150-154, 2005.

[5] H.-J. Song and G.-S. Zhang, "Impact abrasive wear resistance of WC reinforced high manganese steel matrix composites," Foundry Technology, vol. 26, no. 6, pp. 468-469, 2005.

[6] D. H. Lu, "Fabrication and mechanical properties of high manganese steel composites reinforced with in-situ TiC particles," Foundry Technology, vol. 25, no. 2, pp. 120-122, 2004.

[7] G. Zhang, G. Liu, J. Xing, Y. Gao, and J. Chen, "Fabrication and impact wear resistance of $\mathrm{WC}_{\mathrm{p}} / \mathrm{Mn} 13$ surface composites," Journal of Xi'an Jiaotong University, vol. 39, no. 7, pp. 757-761, 2005.

[8] J. Heidemeyer, "Influence of the plastic deformation of metals during mixed friction on their chemical reaction rate," Wear, vol. 66, no. 3, pp. 379-387, 1981.

[9] Y.-Y. Yang, H.-S. Fang, Y.-K. Zheng, Z.-G. Yang, and Z.-L. Jiang, "The failure models induced by white layers during impact wear," Wear, vol. 185, no. 1-2, pp. 17-22, 1995. 

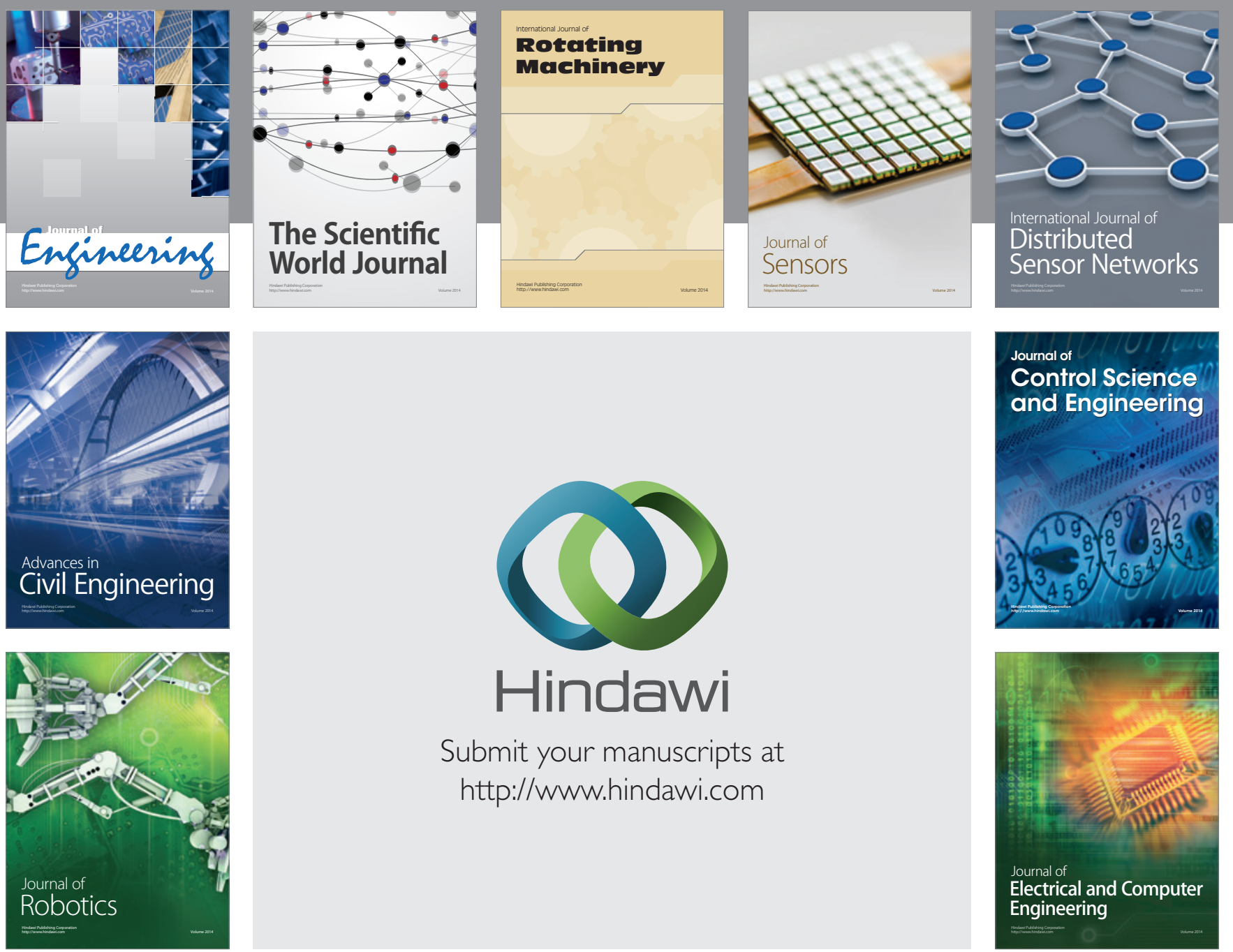

Submit your manuscripts at

http://www.hindawi.com
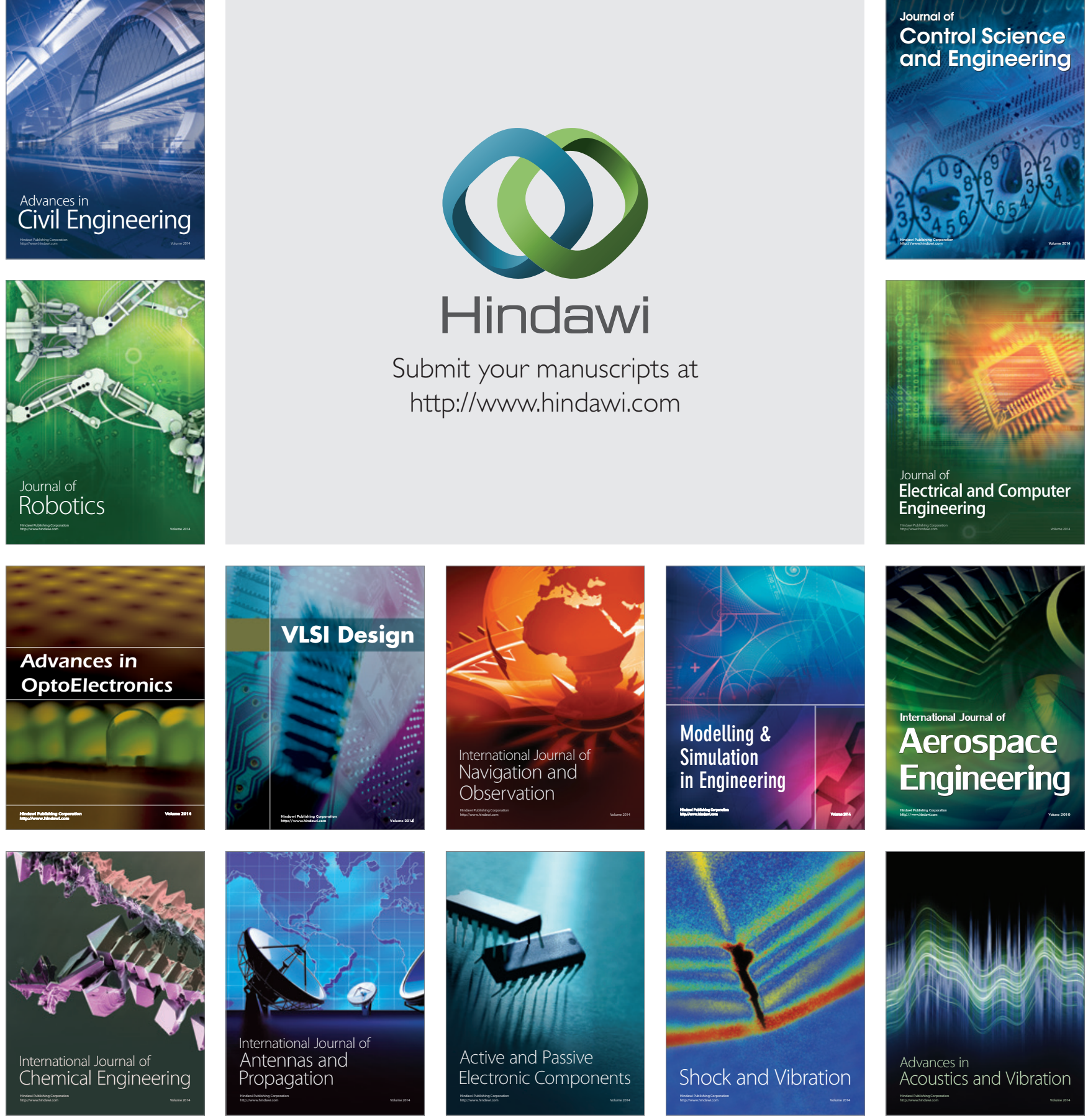